\title{
Home-Based Resistance Training in Heart Diseases: Don't Stop the Music, your Muscles are still Listening
}

\author{
Gabriel Dias Rodrigues ${ }^{1,2}$ and Pedro Paulo da Silva Soares ${ }^{1,2}(\mathbb{0}$ \\ Laboratory of Experimental and Applied Exercise Physiology, Department of Physiology and Pharmacology, Fluminense Federal University, ${ }^{1}$ Niterói - Brazil. \\ National Institute for Science \& Technology - INCT Physical (In)activity \& Exercise, CNPq ${ }^{2}$ - Niterói, RJ - Brazil. \\ Editorial referring to the article: Short-Term Effects of a Resistance Training Program Using Elastic Tubing in Patients with Heart Disease
}

Cardiovascular diseases (CVDs) are a well-known cause of death and physical incapacity worldwide. Heart failure (HF) is a common disease resulting from multiple etiologies that contribute to decreasing physical capacity and quality of life (QOL). ${ }^{1,2}$ Not long ago physical exercises were discouraged in CVDs, but evidence-based exercise programs augment QOL, reduce mortality and hospital readmission in $\mathrm{HF}^{2}$. Strength training is an important component of a cardiac rehabilitation program due to its close relationship with improvements in functional capacity reverberating in activities of daily living and QOL. ${ }^{1}$

Unfortunately, supervised-rehabilitation programs in fitness centers are not widely available for the majority of patients with heart disease. Nevertheless, home-based rehabilitation programs could be more accessible to most patients, because of its relatively low cost and feasibility. ${ }^{2}$ Especially during COVID-19 pandemic lockdown, many opportunities to exercise were suspended, including cardiac rehabilitation services and community health programs. ${ }^{3}$ Also, social distancing increased sedentarism numbers and several position statements have encouraged people to stay active at home, trying to reverse or counterbalance the additional impact of social distance on physical inactivity., ${ }^{3,4}$ In a practical perspective, resistance training is conventionally performed through free weights or weight machines that usually require extensive physical space and outside facilities (i.e., gym or rehabilitation centers). Thus,

\section{Keywords}

Cardiovascular Diseases/complications; COVID-19; Cardiac Rehabilitaion; Betacoronavirus; Heart Failure; Resistance Training; Social Distance; Music. resistance exercises, in particular, are not easily adopted at home and could be omitted from home-based cardiac rehabilitation. To underscore, a question that must be made: How patients remain strong at home?

In the current issue of the International Journal of Cardiovascular Sciences, Silva and colleagues ${ }^{5}$ demonstrated that short-term resistance training with elastic tubing improved peripheral muscle strength and functional capacity in adults (45-79 yrs.) with heart disease in phase II of cardiovascular rehabilitation. Resistance training using elastic tubing is a low-cost and practical tool to increase neuromuscular activation in specific rehabilitation settings with a minimal risk of injury. ${ }^{6}$ It was demonstrated that resistance training with elastic tubing promoted similar positive effects on peripheral muscle strength and functional capacity in the elderly compared to conventional resistance training using weight machines. ${ }^{7}$ In patients with chronic obstructive pulmonary disease (COPD), resistance training using elastic tubing had a greater effect on functional exercise capacity compared to traditional resistance training. Regarding muscle strength and quality of life improvements, elastic tubing was equal to traditional resistance training in COPD. ${ }^{8}$ When performed at home, resistance training with elastic tubing program improved strength after twelve weeks in older adults. ${ }^{9}$ Lastly, elastic tubing-based resistance training showed great selfefficacy and adherence to home-based rehabilitation. ${ }^{10}$

In conclusion, resistance training with elastic tubing seems to be a feasible low-cost and practical alternative to improve or maintain the peripheral muscle strength in heart disease, becoming a potential strategy to be part of a home-based rehabilitation program to counterbalance the home isolation effect on physical capacity and clinical outcomes. 


\section{References}

1. Oka RK, DeMarco T, Haskell WL, Botvinick E, Dae MW, Bolen K, Chatterjee $\mathrm{K}$. Impact of a home-based walking and resistance training program on quality of life in patients with heart failure. Am J Cardiol. 2000; 85: 365-369.

2. Kraal JJ, Van den Akker-van Marle ME, Abu-Hanna A, et al. Clinical and cost-effectiveness of home-based cardiac rehabilitation compared to conventional, centre- based cardiac rehabilitation: Results of the FIT@ Home study. Eur J Prev Cardiol 2017; 24: 1260-1273

3. Peçanha T, Goessler KF, Roschel H, Gualano B. Social isolation during the COVID-19 pandemic can increase physical inactivity and the global burden of cardiovascular disease. Am. J. Physiol. Heart Circ. Physiol. 2020; 318: 1441-1446.

4. Rodrigues GD, Alves Junior ED, Soares PPS. Stay active, stay at home and stay safe: the risk of falls in older adults in the COVID-19 quarantine. Geriatr Gerontol Aging.2020; 14(3):216-217.

5. Silva JPLN, Ferreira TIS, Cavalleri GC, Cruz MMA, Galindo BP, Silva NT, Silva BSA, et al. Short-Term Effects of a Resistance Training Program Using Elastic Tubing in Patients with Heart Disease. Int J Cardiovasc Sci. 2021; 34(2):149-156
6. Melchiorri G, Rainoldi A. Muscle fatigue induced by two different resistances: Elastic tubing versus weight machines. J Electromyogr Kinesiol. 2011; 21(6): 954-9.

7. Lima FF, Camillo CA, Gobbo LA, Trevisan IB, Nascimento W, Silva BSA, et al. Resistance training using low-cost elastic tubing is equally effective to conventional weight machines in middle-aged to older healthy adults: a quasi-randomized controlled clinical trial. J Sports Sci Med. 2018;17(1):153-60.

8. Ramos EM, de Toledo-Arruda AC, Fosco LC, et al. The effects of elastic tubing-based resistance training compared with conventional resistance training in patients with moderate chronic obstructive pulmonary disease: a randomized clinical trial. Clin Rehabil 2014; 28: 1096-1106.

9. Mikesky A, Topp R, Wigglesworth J, Harsha J, Edwards J. Efficacy of a home-based resistance training program for older adults using elastic tubing. Eur J Appl Physiol. 1994; 69(10): 316-320.

10. Millen JA, Bray SR. Self-efficacy and adherence to exercise during and as a follow-up to cardiac rehabilitation. Journal of Applied Social Psychology. 2008; 38: 2072-2087. 